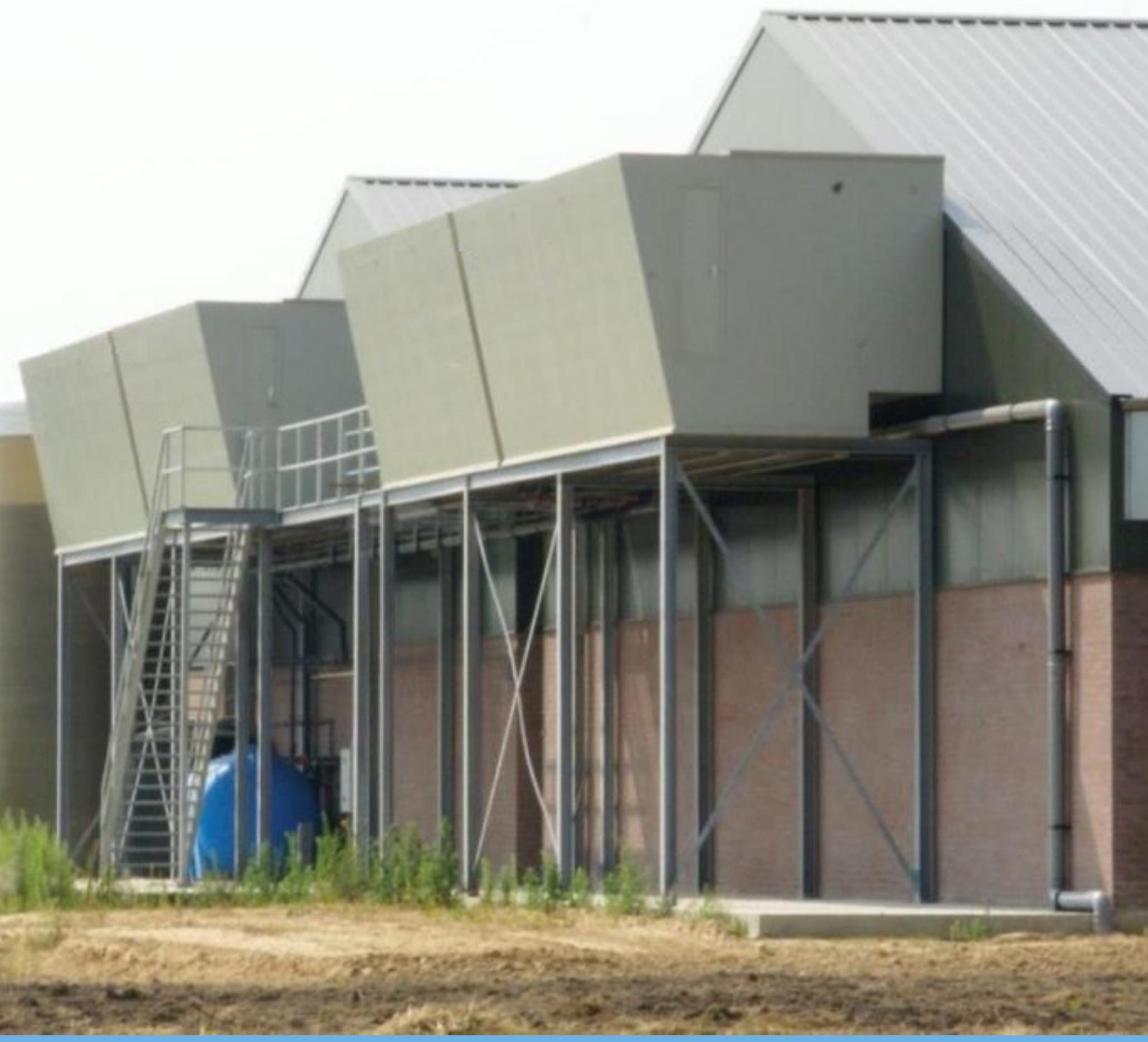

Emissies van stikstofverbindingen uit luchtwassers met biologische wasstap

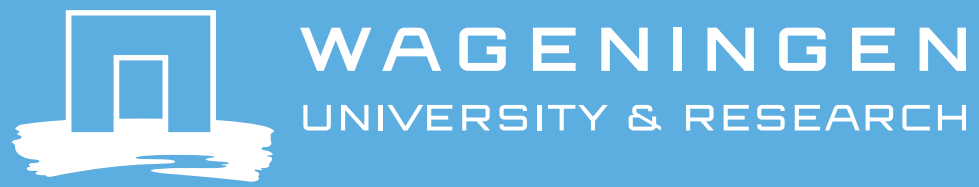





\section{Emissies van stikstofverbindingen uit luchtwassers met biologische wasstap}

R.W. Melse, G.M. Nijeboer, G.C.C. Kupers, J.P.M. Ploegaert

Dit onderzoek is uitgevoerd door Wageningen Livestock Research, in opdracht van en gefinancierd door het Ministerie van Infrastructuur en Waterstaat

Wageningen Livestock Research

Wageningen, juni 2018 
Melse, R.W., G.M. Nijeboer, G.C.C. Kupers, J.P.M. Ploegaert, 2018.

Emissie van stikstofverbindingen uit luchtwassers met biologische wasstap. Wageningen Livestock Research, Rapport 1112.

\section{Samenvatting}

In de regel wordt aangenomen dat in luchtwassers met een biologische behandelingsstap ammoniak uit stallucht wordt omgezet in nitraat en nitriet, dat vervolgens met het spuiwater wordt afgevoerd. Er zijn echter aanwijzingen dat onder bepaalde condities (grote) hoeveelheden andere gasvormige stikstofverbindingen kunnen ontstaan en emitteren. Uit de steekproef die is uitgevoerd, blijkt dat bij biologische luchtwassers met een lage $\mathrm{pH}(<6,5)$ grote hoeveelheden stikstofoxyden $\left(\mathrm{NO}_{\mathrm{y}}\right)$ kunnen ontwijken naar de lucht. Voor dergelijk luchtwassers is de netto stikstofverwijdering veel lager dan de ammoniakverwijdering.

\section{Summary}

In a biotrickling filter treating animal house exhaust air, ammonia is usually converted to dissolved nitrite and nitrate and subsequently removed with the discharge water. However, under certain operating conditions other types of gaseous nitrogen compounds may be emitted to the air. From the survey that was conducted it follows that at low $\mathrm{pH}$ values $(<6.5)$ large amounts of gaseous nitrogen oxides $\left(\mathrm{NO}_{\mathrm{y}}\right)$ may be emitted from biotrickling filters. As a result, the net nitrogen removal of these scrubbers is much lower than the ammonia removal efficiency.

Dit rapport is gratis te downloaden op https://doi.org/10.18174/452686 of op www.wur.nl/livestock-research (onder Wageningen Livestock Research publicaties).

\section{(C) 2018 Wageningen Livestock Research}

Postbus 338, 6700 AH Wageningen, T 03174839 53, E info.livestockresearch@wur.nl, www.wur.nl/livestock-research. Wageningen Livestock Research is onderdeel van Wageningen University \& Research.

Wageningen Livestock Research aanvaardt geen aansprakelijkheid voor eventuele schade voortvloeiend uit het gebruik van de resultaten van dit onderzoek of de toepassing van de adviezen.

Alle rechten voorbehouden. Niets uit deze uitgave mag worden vermenigvuldigd en/of openbaar gemaakt worden door middel van druk, fotokopie, microfilm of op welke wijze dan ook zonder voorafgaande toestemming van de uitgever of auteur.

Wageningen Livestock Research is NEN-EN-ISO 9001:2015 gecertificeerd.

Op al onze onderzoeksopdrachten zijn de Algemene Voorwaarden van de Animal Sciences Group van toepassing. Deze zijn gedeponeerd bij de Arrondissementsrechtbank Zwolle. 


\section{Inhoud}

1

$\begin{array}{ll}\text { Inleiding } & \mathbf{5}\end{array}$

2

$\begin{array}{ll}\text { Materiaal en methoden } & 6\end{array}$

2.1 Selectie luchtwassers en karakterisering

6

2.2 Metingen

6

2.3 Verwerking resultaten

Bijlage 1 Metingen aan luchtwassers

Bijlage 2 Metingen aan luchtwassers (vervolg) 15

Literatuur 


\section{$1 \quad$ Inleiding}

Binnen de intensieve veehouderij wordt veelvuldig gebruik gemaakt van luchtwassers om de emissie uit stallen te beperken. Een van de beschikbare luchtwastechnieken betreft de biologische behandeling van de stallucht. Deze techniek wordt zowel toegepast in de een-traps biologische luchtwassers als in het merendeel van de meer-traps biologische combi-wassers. In het vervolg van het rapport wordt gemakshalve gesproken over biowassers of biologische luchtwassers, waarmee ook de combi-wasser wordt bedoeld die een biologische wasstap heeft.

In dit type biologische wassystemen wordt een deel van de ammoniak $\left(\mathrm{NH}_{3}\right)$ in de stallucht door bacteriën omgezet in het goed wateroplosbare nitriet $\left(\mathrm{NO}_{2}{ }^{-}\right)$en nitraat $\left(\mathrm{NO}_{3}{ }^{-}\right)$middels een proces dat 'nitrificatie' wordt genoemd; dit gaat gepaard gaat met een $\mathrm{pH}$ verlaging. In plaats van te spreken over nitriet en nitraat, kan ook gezegd worden dat er salpeterigzuur $\left(\mathrm{HNO}_{2}\right)$ en salpeterzuur $\left(\mathrm{HNO}_{3}\right)$ wordt geproduceerd. De $\mathrm{pH}$ verlaging als gevolg van deze zuurproductie is de drijvende kracht voor de ammoniakverwijdering (Van der Heyden, 2017), aangezien de $\mathrm{NH}_{3}$ uit de luchtfase dan gemakkelijk kan oplossen als ammonium $\left(\mathrm{NH}_{4}^{+}\right)$. Vervolgens worden de geproduceerde verbindingen, met als tegen-ion ammonium $\left(\mathrm{NH}_{4}{ }^{+}\right.$), in de vorm van opgelost $\mathrm{NH}_{4} \mathrm{NO}_{2}$ (ammoniumnitriet) en $\mathrm{NH}_{4} \mathrm{NO}_{3}$ (ammoniumnitraat) met het spuiwater uit het systeem afgevoerd.

Om het proces van ammoniakverwijdering goed te laten verlopen wordt aangenomen dat de $\mathrm{pH}$ van het waswater ca. 6,5 - 7,5 dient te bedragen (Melse \& Ogink, 2005). Deze pH range is als eis opgenomen in de vigerende regelgeving voor biologische luchtwassers bij stallen. Dit $\mathrm{pH}$ evenwicht komt tot stand doordat enerzijds zuur wordt geproduceerd en een base $\left(\mathrm{NH}_{3}\right)$ in het water wordt ingevangen, en anderzijds (enigszins) zuur waswater wordt afgevoerd uit het systeem en aangevuld wordt met vers water. Het is bekend dat bij normaal functionerende biologische luchtwassers een hoeveelheid lachgas $\left(\mathrm{N}_{2} \mathrm{O}\right)$ en stikstofmonoxide (NO) kan ontstaan; in de regel wordt bij dit type luchtwassers $1-5 \%$ van de stikstof uit de ammoniak in de stallucht omgezet in $\mathrm{N}_{2} \mathrm{O}$; de productie van $\mathrm{NO}$ is in het algemeen lager (Melse \& Mosquera, 2014). Lachgas is een sterk broeikasgas (Greenhouse Warming Potential $=265$ ) en stikstofmonoxide kan na depositie leiden tot verzuring en eutrofiëring van de bodem.

Uit een eerder uitgevoerde steekproef (Melse et al., 2015), waarbij 36 enkelvoudige biologische luchtwassers werden bemonsterd, bleek echter dat in een aantal gevallen (25\% van de locaties) de $\mathrm{pH}$ van het waswater lager was dan 6,5; bij drie van de luchtwassers werden zelfs $\mathrm{pH}$-waarden $\leq 4$ gevonden, een waarde die normaal is voor chemische luchtwassers waarbij zwavelzuur wordt toegevoegd om ammoniak af te vangen. Zoals in Melse et al. (2015) wordt besproken, is uit de literatuur bekend dat het nitrificatieproces bij een pH lager dan ca. 6,5 geremd kan worden (Painter, 1986; Shammas, 1986; Burton en Prosser, 2001), ook al is in sommige onderzoeken aangetoond dat ook bij lage pH nitrificatie kan voorkomen (De Boer et al., 1991; Tarre en Green, 2004; Tarre et al., 2004). Verder is het zo dat wanneer de nitrificatie door lage pH geremd wordt, dit kan leiden tot een verhoogde productie van lachgas (Mørkved et al., 2007) en stikstofmonoxide (Groeneweg et al., 1996). Daarnaast is bekend dat het toepassen van denitrificatiesystemen kan leiden tot een hoge emissie van lachgas.

Met deze achtergrond heeft het Ministerie van Infrastructuur en Waterstaat aan Wageningen Livestock Research gevraagd een oriënterend onderzoek uit te voeren naar de emissie van stikstofverbindingen uit luchtwassers met een biologische behandelingsstap. Het doel van het onderzoek was om na te gaan of er bij de verschillende type luchtwassystemen inderdaad hoge emissies van stikstofverbindingen (anders dan ammoniak) kunnen optreden. De verschillende typen luchtwassers betroffen biowassers met lage $\mathrm{pH}$, met normale $\mathrm{pH}$ en met hoge $\mathrm{pH}$; daarnaast zijn biowassers met een nageschakelde denitrificatie-unit onderzocht. 


\section{$2 \quad$ Materiaal en methoden}

\subsection{Selectie luchtwassers en karakterisering}

Bij diverse luchtwasserleveranciers is nagevraagd of zij in het klantenbestand biowassers hadden waarvan bekend was dat deze een lage waswater $\mathrm{pH}$ heeft $(<6,5)$ en biowassers waarvan bekend is dat deze een normale $\mathrm{pH}(6,5<\mathrm{pH}<7,5)$ of hogere $\mathrm{pH}$ hebben $(\mathrm{pH}>7,5)$. Daarnaast is gevraagd naar biowassers met een nageschakelde denitrificatie-unit. Op basis van deze reacties en een eigen adressenbestand is een 15-tal veehouders gevonden die wilden meewerken aan het onderzoek en deze locaties zijn bezocht in de periode april - oktober 2017. Alle locaties betroffen varkensstallen.

De luchtwasserlocaties zijn ingedeeld in 4 categorieën:

- categorie A t/m C betreffen biologische wassers met repectievelijk een lage, normale of hoge $\mathrm{pH}$, waarbij het gaat om een één-traps biologische wasser of een meer-traps biologische combi-wasser, zonder dat sprake is van een nageschakelde denitrificatie-unit;

- categorie D betreft een luchtwasser waarbij sprake is van een nageschakelde denitrificatie-unit.

\subsection{Metingen}

Op elke bedrijfslocatie is een monster genomen van het waswater en zijn meteen de pH (zuurgraad), de EC (elektrische geleidbaarheid) en de temperatuur van het waswatermonster bepaald. Vervolgens is in het laboratorium de concentratie van ammonium, nitriet en nitraat bepaald; ook is het drogestofgehalte en de asrest bepaald.

Daarnaast is in duplo de ammoniakconcentratie van de ingaande en uitgaande lucht van de biowasser indicatief gemeten met behulp van gasdetectiebuisjes (Kitagawa, type 105SC: 5 - 260 ppm en type 105SD: 0,2 - 20 ppm). Uit eerder onderzoek blijkt dat dit type meting een goede indicatie geeft van de concentraties, maar dat de verwijderingsrendementen enigszins kunnen worden overschat (Melse et al., 2012a).

Tenslotte is een luchtmonster genomen van de ingaande en uitgaande lucht middels de zogenaamde longmethode (Mol \& Ogink, 2002), zoals die ook wordt toegepast voor het nemen van geurmonsters. Hierbij wordt een lege nalophaan (PET) monsterzak (40 liter), die zich in een gesloten vat bevindt, via een Teflon slang voor gevuld met te bemonsteren lucht. Door lucht uit het vat te zuigen $\left(0,51 \mathrm{~min}^{-1}\right)$, ontstaat in het vat onderdruk en wordt door een stoffilter $(1-2 \mu \mathrm{m})$ de te bemonsteren lucht aangezogen zodat deze in de zak terecht komt. Binnen 24 uur zijn de concentraties van lachgas en stikstofoxiden in de monsterzakken bepaald. De concentratie lachgas werd gaschromatografisch bepaald (Carbo Erba Instruments, GC 8000 Top; column: Haysep; detector: ECD/HWD). De concentratie van overige stikstofoxiden werd bepaald met een chemoluminiscentie stikstofoxiden analyzer ( $\mathrm{NO}_{x}$ analyzer, API Advanced Pollution Instrumentation, Model 200A). De chemoluminiscentie analyzer werd geijkt met behulp van $\mathrm{N}_{2}$ (nul-gas), $\mathrm{NO}$ (40 ppm) en $\mathrm{NO}_{2}$ (11 ppm).

Naast het detecteren van $\mathrm{NO}$ en $\mathrm{NO}_{2}$ (die tezamen meestal als $\mathrm{NO}_{x}$ worden aangeduid), worden ook andere stikstofoxiden gedetecteerd door een chemoluminiscentie analyzer. Hierbij gaat het bijvoorbeeld om organische nitriet- en nitraatverbindingen, salpeterigzuur, salpeterzuur en peroxyacetyl nitrate (PAN) (Harrison, 1986), die aangeduid worden als ' $\mathrm{NO}_{z}$ '. Bij elkaar kunnen deze stikstofoxiden worden aangeduid als ' $\mathrm{NO}_{y}$ ', waarbij $\mathrm{NO}_{y}=\mathrm{NO}_{z}+\mathrm{NO}_{\mathrm{x}}$. Daarom wordt de met de chemoluminiscentie analyzer gemeten concentratie stikstofoxiden aangeduid als 'concentratie $\mathrm{NO}_{y}$ '. Lachgas en ammoniak zijn daarbij dus niet inbegrepen. 


\subsection{Verwerking resultaten}

De werking van een biowasser kan met betrekking tot de verwijdering en productie van stikstofverbindingen op verschillende wijzen worden beschreven. In dit rapport wordt hiervoor een aantal kentallen berekend:

- Rendement $\mathrm{NH}_{3}$ verwijdering, in \%;

- Deel van $\mathrm{NH}_{3}-\mathrm{N}$ ingaand wat als $\mathrm{N}_{2} \mathrm{O}-\mathrm{N}$ gas emitteert, in \%;

- Deel van $\mathrm{NH}_{3}-\mathrm{N}$ ingaand wat als $\mathrm{NO}_{y}-\mathrm{N}$ gas emitteert, in \%;

- Netto N verwijdering.

Onderstaand wordt voor elk begrip toegelicht wat het betekent en op welke wijze dit kan worden berekend. Hierbij moet bedacht worden dat de "ingaande lucht van de wasser" hetzelfde is als de "stallucht".

Rendement $\mathrm{NH}_{3}$ verwijdering (\%)

Het ammoniakverwijderingsrendement van een luchtwasser geeft aan welke percentage van de ammoniak uit de stallucht wordt afgevangen door de luchtwasser. Dit kan als volgt worden berekend:

Rendement $\mathrm{NH}_{3}$ verwijdering $(\%)=\left(1-\left[\mathrm{NH}_{3}\right]_{\text {uit }} /\left[\mathrm{NH}_{3}\right]_{\text {in }}\right) \times 100 \%$

waarbij:

$\left[\mathrm{NH}_{3}\right]_{\text {in }}=\quad$ concentratie van $\mathrm{NH}_{3}$ in ingaande lucht van wasser, $\mathrm{mg} \mathrm{NH} / \mathrm{m}^{3}$

$\left[\mathrm{NH}_{3}\right]_{\text {uit }}=$ concentratie van $\mathrm{NH}_{3}$ in uitgaande lucht van wasser, $\mathrm{mg} \mathrm{NH} / \mathrm{m}^{3}$

Zoals uit de berekening blijkt, is deze louter en alleen gebaseerd op $\mathrm{NH}_{3}$ en wordt geen rekening gehouden met de eventuele productie of verwijdering van andere stikstofverbindingen.

\section{Deel van $\mathrm{NH}_{3}-\mathrm{N}$ ingaand wat als $\mathrm{N}_{2} \mathrm{O}-\mathrm{N}$ gas emitteert (\%)}

In een biowasser kan enig lachgas ontstaan als ongewenst bijproduct van de biologische omzetting van ammoniak. Daarnaast zal de stallucht al enig lachgas bevatten. Om na te gaan welk deel van de ammoniak uit de stallucht wordt omgezet in lachgas, kan deze berekening worden uitgevoerd:

$$
\begin{aligned}
& \text { Deel van } \mathrm{NH}_{3}-\mathrm{N} \text { ingaand wat als } \mathrm{N}_{2} \mathrm{O}-\mathrm{N}(\mathrm{g}) \text { emitteert }(\%)= \\
& \left(\left[\mathrm{N}_{2} \mathrm{O}-\mathrm{N}\right]_{\text {uit }}-\left[\mathrm{N}_{2} \mathrm{O}-\mathrm{N}\right]_{\text {in }}\right) /\left[\mathrm{NH}_{3}-\mathrm{N}\right]_{\text {in }} \times 100 \%
\end{aligned}
$$

waarbij:

$\left[\mathrm{NH}_{3}-\mathrm{N}\right]_{\text {in }}=\quad$ concentratie van $\mathrm{NH}_{3}-\mathrm{N}$ in ingaande lucht van wasser, $\mathrm{mg} \mathrm{N} / \mathrm{m}^{3}$

$\left[\mathrm{N}_{2} \mathrm{O}-\mathrm{N}\right]_{\text {in }} \quad=\quad$ concentratie van $\mathrm{N}_{2} \mathrm{O}-\mathrm{N}$ in ingaande lucht van wasser, $\mathrm{mg} \mathrm{N} / \mathrm{m}^{3}$

$\left[\mathrm{N}_{2} \mathrm{O}-\mathrm{N}\right]_{\text {uit }} \quad=\quad$ concentratie van $\mathrm{N}_{2} \mathrm{O}-\mathrm{N}$ in uitgaande lucht van wasser, $\mathrm{mg} \mathrm{N} / \mathrm{m}^{3}$

Op deze wijze wordt uitgedrukt welke fractie van de totale hoeveelheid ammoniak-stikstof uit de ingaande lucht in de luchtwasser wordt omgezet in lachgas.

\section{Deel van $\mathrm{NH}_{3}-\mathrm{N}$ ingaand wat als $\mathrm{NO}_{y}-\mathrm{N}$ gas emitteert (\%)}

Daarnaast kunnen in een biowasser naast $\mathrm{N}_{2} \mathrm{O}$ nog andere stikstofoxiden ontstaan en emitteren in de vorm van $\mathrm{NO}_{y}$. Bovendien zal de stallucht al een kleine hoeveelheid stikstofoxiden bevatten. Om na te gaan welk deel van de ammoniak uit de stallucht wordt omgezet in $\mathrm{NO}_{\mathrm{y}}$, kan (op vergelijkbare wijze als hierboven voor lachgas) deze berekening worden uitgevoerd:

$$
\begin{aligned}
& \text { Deel van } \mathrm{NH}_{3}-\mathrm{N} \text { ingaand wat als } \mathrm{NO}_{y}-\mathrm{N}(\mathrm{g}) \text { emitteert }(\%)= \\
& \left(\left[N O_{y}-\mathrm{N}\right]_{\text {uit }}-\left[\mathrm{NO} \mathrm{O}_{y}-\mathrm{N}\right]_{\text {in }}\right) /[\mathrm{NH}-\mathrm{N}]_{\text {in }} \times 100 \%
\end{aligned}
$$

waarbij:

$\left[\mathrm{NH}_{3}-\mathrm{N}\right]_{\text {in }} \quad=\quad$ concentratie van $\mathrm{NH}_{3}-\mathrm{N}$ in ingaande lucht van wasser, $\mathrm{mg} \mathrm{N} / \mathrm{m}^{3}$

$\left[\mathrm{NO}_{y}-\mathrm{N}\right]_{\text {in }} \quad=\quad$ concentratie van $\mathrm{NO}_{y}-\mathrm{N}$ in ingaande lucht van wasser, $\mathrm{mg} \mathrm{N} / \mathrm{m}^{3}$ 
$\left[\mathrm{NO}_{y}-\mathrm{N}\right]_{u i t} \quad=\quad$ concentratie van $\mathrm{NO}_{y}-\mathrm{N}$ in uitgaande lucht van wasser, $\mathrm{mg} \mathrm{N} / \mathrm{m}^{3}$

Op deze wijze wordt uitgedrukt welke fractie van de totale hoeveelheid ammoniak-stikstof uit de ingaande lucht in de luchtwasser wordt omgezet in stikstofoxiden.

Netto $\mathrm{N}$ verwijdering (\%)

Bovenstaand werd uitgerekend wat de ammoniakverwijdering van een luchtwasser is. Wanneer er naast het verwijderen van ammoniak echter sprake is van de productie van andere

stikstofverbindingen (zoals $\mathrm{N}_{2} \mathrm{O}$ en $\mathrm{NO}_{y}$ ), is de netto verwijdering van stikstof lager dan de berekende ammoniakverwijdering. Onderstaand wordt de netto stikstofverwijdering van een luchtwasser berekend, rekening houdend met zowel $\mathrm{NH}_{3}$ als ook de productie van $\mathrm{N}_{2} \mathrm{O}$ en $\mathrm{NO}_{y}$ :

Netto $N$ verwijdering (\%)

$=\left(1-[N \text {-totaal }]_{\text {uit }} /[N \text {-totaal }]_{\text {in }}\right) \times 100 \%$

$=\left(1-\left(\left[\mathrm{NH}_{3}\right]_{u i t}+\left[\mathrm{N}_{2} \mathrm{O}-\mathrm{N}\right]_{u i t}+\left[\mathrm{NO}_{y}-\mathrm{N}\right]_{u i t}\right) /\left(\left[\mathrm{NH}_{3}\right]_{\text {in }}+\left[\mathrm{N}_{2} \mathrm{O}-\mathrm{N}\right]_{\text {in }}+\left[\mathrm{NO}_{y}-\mathrm{N}\right]_{\text {in }}\right)\right) \times 100 \%$

waarbij:

$\left[\mathrm{NH}_{3}-\mathrm{N}\right]_{\text {in }}=\quad$ concentratie van $\mathrm{NH}_{3}-\mathrm{N}$ in ingaande lucht van wasser, $\mathrm{mg} \mathrm{N} / \mathrm{m}^{3}$

$\left[\mathrm{N}_{2} \mathrm{O}-\mathrm{N}\right]_{\text {in }} \quad=\quad$ concentratie van $\mathrm{N}_{2} \mathrm{O}-\mathrm{N}$ in ingaande lucht van wasser, $\mathrm{mg} \mathrm{N} / \mathrm{m}^{3}$

$\left[\mathrm{N}_{2} \mathrm{O}-\mathrm{N}\right]_{u i t} \quad=\quad$ concentratie van $\mathrm{N}_{2} \mathrm{O}-\mathrm{N}$ in uitgaande lucht van wasser, $\mathrm{mg} \mathrm{N} / \mathrm{m}^{3}$

$\left[\mathrm{NO}_{y}-\mathrm{N}\right]_{\text {in }} \quad=\quad$ concentratie van $\mathrm{NO}_{y}-\mathrm{N}$ in ingaande lucht van wasser, $\mathrm{mg} \mathrm{N} / \mathrm{m}^{3}$

$\left[\mathrm{NO}_{y}-\mathrm{N}\right]_{u i t}=\quad$ concentratie van $\mathrm{NO}_{y}-\mathrm{N}$ in uitgaande lucht van wasser, $\mathrm{mg} \mathrm{N} / \mathrm{m}^{3}$ 
Werking luchtwasser: verwijdering en productie van stikstofverbindingen

In Tabel 1 worden de resultaten van de metingen op de verschillende luchtwasserlocaties samengevat. Opgemerkt dient te worden dat het om een steekproef van beperkte omvang gaat (in totaal zijn 15 luchtwassers eenmalig bemeten, aantal luchtwasser per categorie is 2 tot 6) en dat er sprake is van een grote spreiding binnen de categorieën. In Bijlage 1 worden de resultaten van de metingen op de verschillende luchtwasserlocaties in detail weergegeven.

Tabel 1. Ammoniakrendement en deel dat als $\mathrm{N}_{2} \mathrm{O}$ of $\mathrm{NO}_{y}$ emitteert, gemiddelden waarden met standaardfout (sem) tussen haakjes.

\begin{tabular}{lcccc}
\hline Type biowasser & $\begin{array}{l}\text { Rendement } \\
\mathrm{NH}_{3} \\
\text { verwijdering } \\
(\%)\end{array}$ & $\begin{array}{l}\text { Deel van } \mathrm{NH}_{3}-\mathrm{N} \\
\text { ingaand wat als } \\
\mathrm{N}_{2} \mathrm{O} \text { gas emitteert } \\
(\%)\end{array}$ & $\begin{array}{l}\text { Deel van } \mathrm{NH}_{3}-\mathrm{N} \\
\text { ingaand wat als } \\
\mathrm{NO} \text { gas } \\
\text { emitteert }(\%)\end{array}$ & $\begin{array}{l}\text { Netto } \mathrm{N} \\
\text { verwijdering }\end{array}$ \\
\hline A $\quad \begin{array}{l}\text { Standaard ontwerp - lage pH } \\
(\mathrm{pH}<6,5) ; \mathrm{n}=6\end{array}$ & $100(0,0)$ & $4,5(0,7)$ & $61(16)$ & $36(16)$ \\
B $\quad \begin{array}{l}\mathrm{S} \text { tandaard ontwerp - normale } \\
\mathrm{pH}(6,5<\mathrm{pH}<7,5) ; \mathrm{n}=3\end{array}$ & $65(5,3)$ & $1,8(0,9)$ & $0,2(0,0)$ & $62(5,6)$ \\
C $\begin{array}{l}\text { Standaard ontwerp - hoge } \\
\mathrm{pH}(>7,5) ; \mathrm{n}=2\end{array}$ & $22(3,1)$ & $12(12)$ & $-5,7(6,0)(1)$ & $19(4,0)$ \\
D $\begin{array}{l}\text { Denitrificatie-unit aanwezig; } \\
\mathrm{n}=4\end{array}$ & $66(8,8)$ & $10(5,2)$ & $1,1(0,6)$ & $57(5,6)$ \\
\hline
\end{tabular}

$\overline{\left({ }^{1}\right) \mathrm{Bij} \text { deze categorie waren de uitgaande concentraties } \mathrm{NO}_{y} \text { gemiddeld lager dan de ingaande concentraties. }}$

In de eerste kolom van Tabel 1 wordt het $\mathrm{NH}_{3}$ verwijderingsrendement weergegeven, zonder rekening te houden met de productie van eventuele andere gasvormige $\mathrm{N}$-verbindingen.

Hierbij valt op dat de ammoniakverwijdering van categorie A $100 \%$ bedroeg - dit is te verklaren door de lage $\mathrm{pH}$ van het waswater (gemiddeld 4,8 ). Op vergelijkbare wijze werd bij categorie $\mathrm{C}$ met een hoge $\mathrm{pH}$ (gemiddeld 7,6 ) een lage $\mathrm{NH}_{3}$ verwijdering gevonden. De $\mathrm{pH}$ van het waswater is namelijk bepalend voor het ammoniakverwijderingsrendement. Uit de lage pH bij categorie $\mathrm{A}$ kan geconcludeerd worden dat er, ondanks de lage $\mathrm{pH}$, nog steeds nitrificatie plaatsvindt. Als de nitrificatie namelijk geremd of stilgelegd zou zijn (als gevolg van remming van de bacteriën) zou de pH namelijk niet op dit lage niveau blijven maar gaan stijgen door het invangen van ammoniak (een base) uit de stallucht.

De ammoniakverwijderingsrendementen van categorie $\mathrm{B}$ (normale $\mathrm{pH}, \mathrm{pH}$ gemiddelde 7,2 ) en categorie $\mathrm{D}$ (denitrificatie, $\mathrm{pH}$ gemiddelde 7,4 ) bevonden zich tussen de lage en hoge $\mathrm{pH}$ van de categorieën $\mathrm{A}$ en $\mathrm{C}$.

In de tweede kolom van Tabel 1 wordt de productie van lachgas weergegeven, als percentage van de hoeveelheid ammoniakstikstof die zich in de ingaande lucht van de wasser bevindt. De vergelijking is gedaan op massabasis stikstof; weliswaar wordt 1 molecuul $\mathrm{N}_{2} \mathrm{O}$ gevormd uit 2 moleculen $\mathrm{NH}_{3}$, maar 1 gram $\mathrm{N}_{2} \mathrm{O}-\mathrm{N}$ wordt gevormd uit 1 gram $\mathrm{NH}_{3}-\mathrm{N}$. Het is niet duidelijk of de emissie van $\mathrm{N}_{2} \mathrm{O}$ verschillend is voor de verschillende categorieën. Vanwege het kleine aantal metingen en de grote spreiding kunnen kleine verschillen niet worden onderscheiden. Wel is uit eerder onderzoek (Melse et al. 2012b, 2012c; Mosquera et al., 2012; Melse \& Mosquera, 2014) bekend dat bij systemen met een denitrificatie-unit (zoals in categorie $\mathrm{D}$ ) een hoge $\mathrm{N}_{2} \mathrm{O}$ emissie kan worden verwacht.

Op vergelijkbare wijze wordt in de kolom ernaast de productie van ' $\mathrm{NO}_{\mathrm{y}}$ ' weergegegeven, uitgedrukt op massabasis stikstof als percentage van de hoeveelheid ammoniakstikstof in de ingaande lucht. Hierbij valt op dat de biologische luchtwassystemen met een lage $\mathrm{pH}$ een zeer hoge emissie van $\mathrm{NO}_{\mathrm{y}}$ (stikstofoxiden) laten zien: gemiddeld wordt $61 \%$ van de ammoniak in de ingaande lucht in $\mathrm{NO}_{\mathrm{y}}$ componenten omgezet. 
Het gevolg van de productie en emissie van deze gasvormige stikstofcomponenten is dat de netto stikstofverwijdering van een dergelijk systeem een stuk lager kan zijn dan de ammoniakverwijdering uit de eerste kolom. De belangrijkste reden om ammoniakemissie uit stallen tegen te gaan is het terugdringen van de stikstofemissie en de stikstofdepositie die daarvan het gevolg is. Wanneer dan een deel van de ammoniak wordt omgezet in $\mathrm{NO}_{\mathrm{y}}$, heeft dit alsnog stikstofdepositie tot gevolg, aangezien $1 \mathrm{~mol} \mathrm{NH}$ in dezelfde stikstofdepositie resulteert $1 \mathrm{~mol} \mathrm{NO}$. Voor $\mathrm{N}_{2} \mathrm{O}$ geldt dat dit niet leidt tot stikstofdepositie, maar dat dit een sterk broeikasgas is. Hieruit volgt dat de emissie van deze gasvormige componenten ongewenst is en het de voorkeur heeft om de werking van een luchtwasser niet te evalueren op basis van de ammoniakverwijdering maar op basis van het netto stikstofverwijderingsrendement.

Uit vergelijking van de eerste en de laatste kolom van Tabel 1 blijkt het ammoniak- en het stikstofverwijderingsrendement voor de wassers met normale $\mathrm{pH}$ en hoge $\mathrm{pH}$ (categorie $\mathrm{B}$ en $\mathrm{C}$ ) dicht bij elkaar lagen, doordat er weinig $\mathrm{N}_{2} \mathrm{O}$ en $\mathrm{NO}_{y}$ werd gevormd. Het netto

stikstofverwijderingsrendement voor de wassers met denitrificatie-unit (categorie D) lag gemiddeld een kleine $10 \%$ lager dan het ammoniakrendement, als gevolg van de productie van $\mathrm{N}_{2} \mathrm{O}$. Tenslotte lag het stikstofverwijderingsrendement voor de wassers met lage pH (categorie A) meer dan $60 \%$ lager dan het ammoniakrendement, vanwege de zeer hoge emissie van $\mathrm{NO}_{y}$ componenten.

De concentratie van $\mathrm{NO}_{y}$ in de uitgaande lucht van de luchtwassers met lage $\mathrm{pH}$, bedroeg gemiddeld $15 \mathrm{ppm}$ (terwijl dit voor de andere groepen luchtwassers gemiddeld slechts 0,2 ppm is) bij een ingaande $\mathrm{NH}_{3}$ concentratie van gemiddeld $32 \mathrm{ppm}$.

\section{$\mathrm{NO}_{y}$ en salpeterigzuur $\left(\mathrm{HNO}_{2}\right)$}

Zoals opgemerkt is $\mathrm{NO}_{y}$ een verzamelnaam voor alle stikstofoxiden die gemeten kunnen worden met de chemoluminiscentie analyzer. Bekend is dat in een biologische luchtwasser een hoeveelheid NO en $\mathrm{NO}_{2}$, beide gassen, gevormd kan worden maar het is onwaarschijnlijk dat dit zou resulteren in de grote hoeveelheid $\mathrm{NO}_{y}$ die gevonden is bij de luchtwassers met lage $\mathrm{pH}$ (categorie $\mathrm{A}$ ).

Het ligt meer voor de hand dat de gemeten $\mathrm{NO}_{y}$ concentratie (voor het grootste deel) vervluchtiging van salpeterigzuur $\left(\mathrm{HNO}_{2}\right)$ uit de luchtwassser betreft. In het water van een biowasser is namelijk vaak een vrij hoge concentratie nitriet $\left(\mathrm{NO}_{2}^{-}\right)$aanwezig, die kan oplopen tot enige grammen $\mathrm{NO}_{2}^{-}-\mathrm{N}$ per liter. In combinatie met een lage $\mathrm{pH}$ zou dit nitriet kunnen vervluchtigen als salpeterigzuur. In Bijlage 2 worden de gemeten concentraties van $\mathrm{NH}_{4}{ }^{+}, \mathrm{NO}_{2}^{-}$en $\mathrm{NO}_{3}{ }^{-}$in het waswater weergegeven.

In Figuur 1 wordt geïllustreerd welke concentratie gasvormig $\mathrm{HNO}_{2}$ er op theoretische basis verwacht mag worden in de uitgaande lucht van de wasser, afhankelijk van de heersende $\mathrm{pH}$ en de nitrietconcentratie in het waswater, uitgaande van een evenwichtssituatie. 


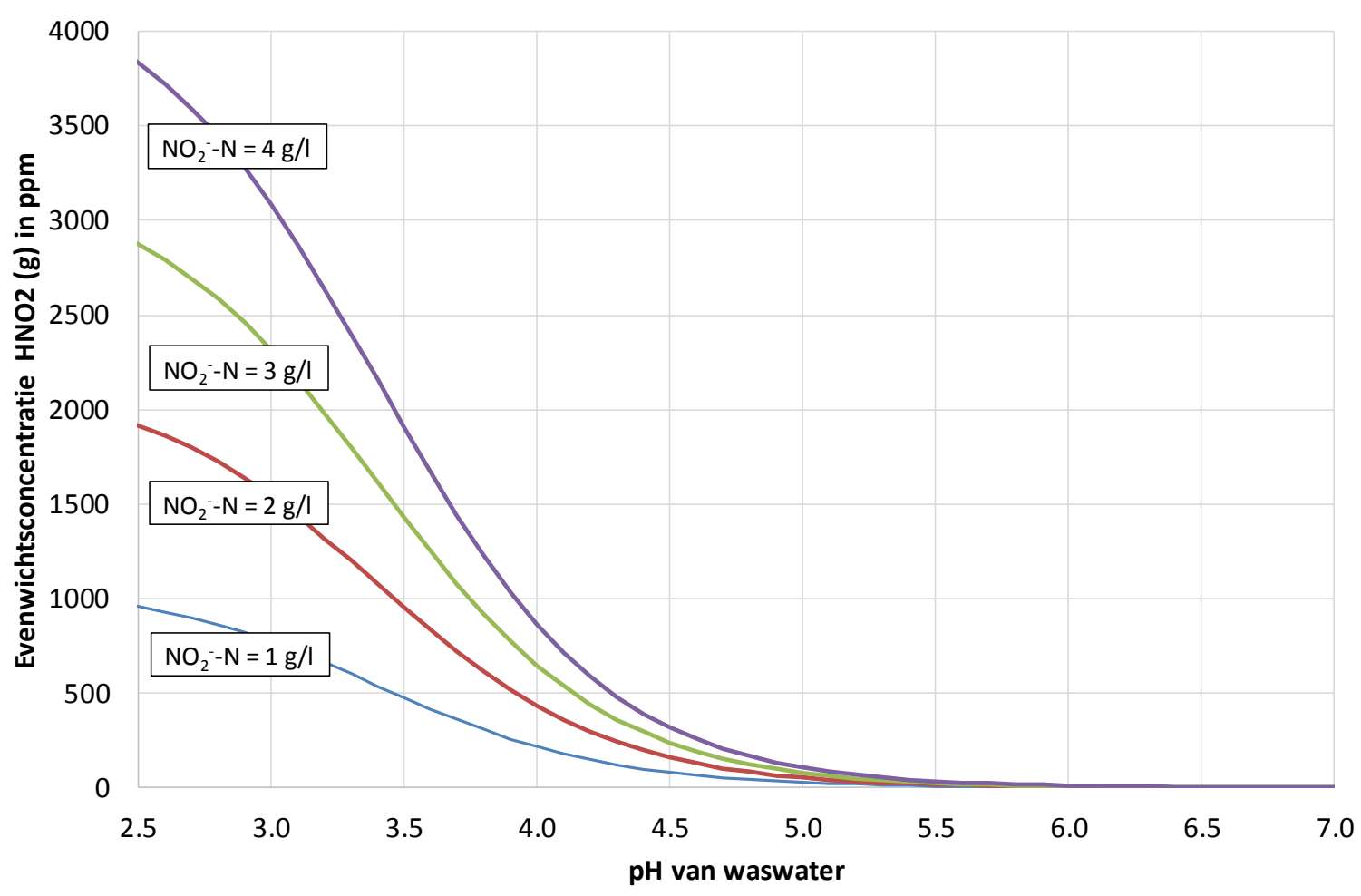

Figuur 1. Evenwichtsconcentratie van salpeterigzuur, $\mathrm{HNO}_{2}(\mathrm{~g})$, in de gasfase, afhankelijk van pH en nitrietconcentratie van de waterfase; $T=20^{\circ} \mathrm{C}$; Henry coëff. $=66 \mathrm{M} / \mathrm{atm}$.

Om de hypothese te testen of de gevonden $\mathrm{NO}_{\mathrm{y}}$ concentratie inderdaad hoofdzakelijk salpeterigzuur betreft, is voor alle uitgevoerde metingen berekend welke concentratie $\mathrm{HNO}_{2}(\mathrm{~g}$ ) op basis van Figuur 1 verwacht mag worden en vervolgens is deze berekende concentratie (zie Bijlage 2) in Figuur 2 uitgezet tegen de gemeten $\mathrm{NO}_{y}$ concentratie (zie Bijlage 1).

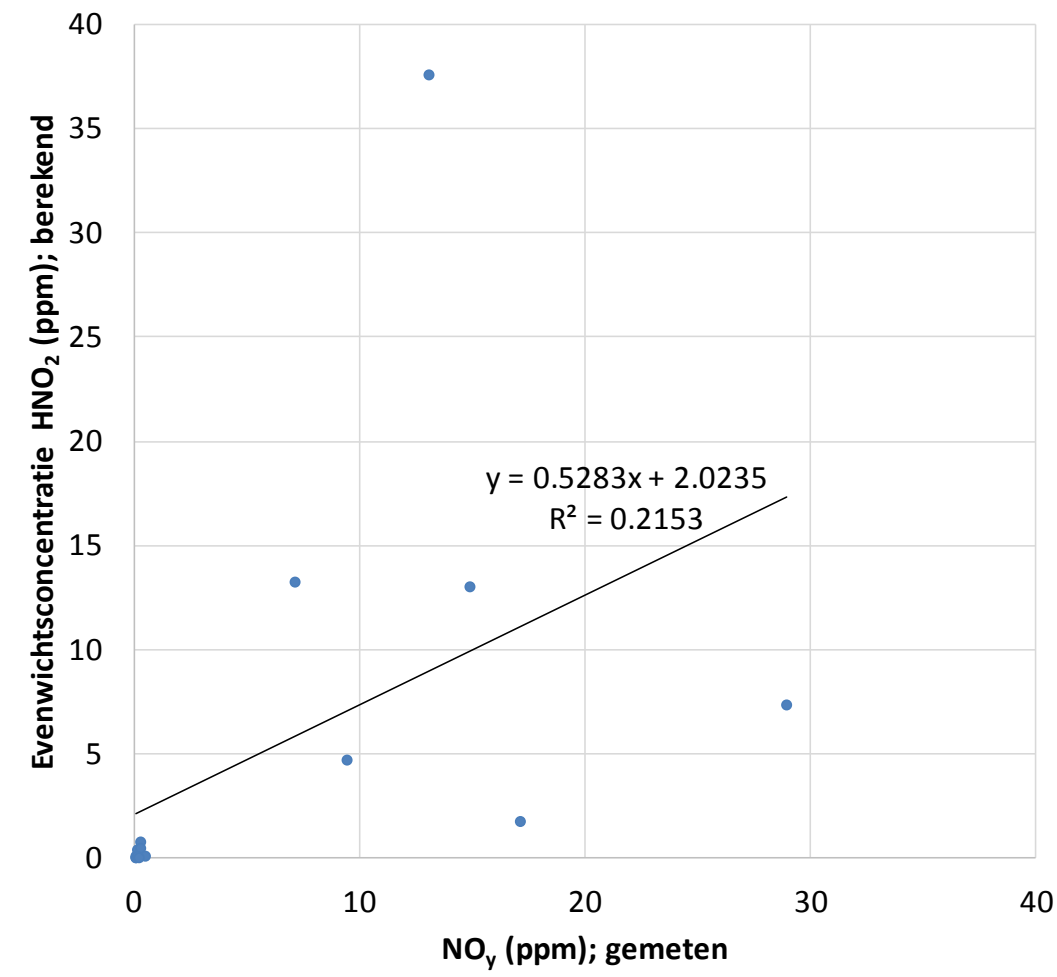

Figuur 2. Berekende evenwichtsconcentratie van salpeterigzuur $\left(\mathrm{HNO}_{2}\right)$ versus de gemeten $\mathrm{NO}_{y}$ concentratie in de uitgaande lucht van de biowassers. 
Uit Figuur 2 blijkt echter dat er sprake is van een zwakke correlatie tussen de berekende $\mathrm{HNO}_{2}$ concentratie en de gemeten $\mathrm{NO}_{y}$ concentratie. Wanneer de uitbijter $(13,38)$ buiten beschouwing wordt gelaten neemt $R^{2}$ toe tot 0,37 maar is nog steeds sprake van een richtingscoefficent $(\mathrm{nl} .0,3)$ die ver af ligt van de verwachte $1: 1$ verhouding. Dit betekent dat de gemeten $\mathrm{NO}_{\mathrm{y}}$ concentratie slechts deels verklaard kan worden op basis van de berekende evenwichtsconcentratie $\mathrm{HNO}_{2}$.

Hierbij moet bedacht worden dat het aantal metingen slechts beperkt is.

NOy en $\mathrm{pH}$

Wel blijkt dat er een sterke correlatie bestaat tussen de gemeten concentratie en emissie van $\mathrm{NO}_{y}$ en de $\mathrm{pH}$ van het waswater, zoals in Figuur 3 wordt weergegeven. In alle gevallen waarbij hoge $\mathrm{NO}_{\mathrm{y}}$ concentraties zijn gemeten (7-29 ppm; gemiddeld 15 ppm) was sprake van een $\mathrm{pH}$ van het waswater lager dan ca. 6,5 (2,8-6,3; gemiddeld 4.8); wanneer de pH van het waswater hoger was dan ca. 6,5 $(6,8-7,7 ;$ gemiddeld 7,4$)$ was de $\mathrm{NO}_{\mathrm{y}}$ concentratie zeer laag $(\leq 0,5 \mathrm{ppm})$.

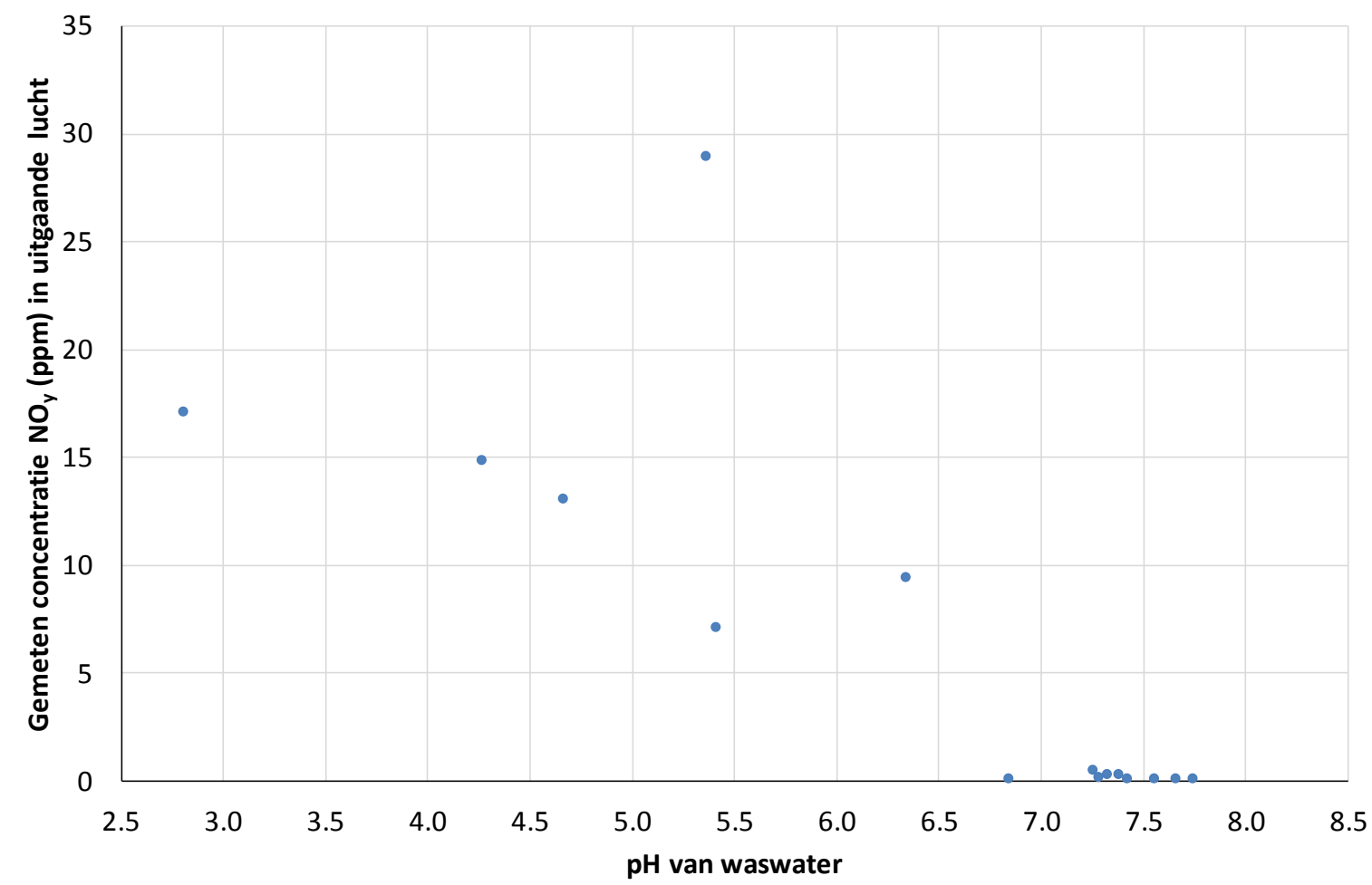

Figuur 3. Gemeten concentratie $N O_{y}$ in uitgaande lucht van biowasser versus de $\mathrm{pH}$ van het waswater. 


\section{$4 \quad$ Conclusies en aanbevelingen}

Uit een (beperkte) steekproef die is uitgevoerd op een aantal locaties met een biowasser (d.w.z. een één-traps biologische luchtwasser of een meer-traps biologische combi-wasser) is het volgende gebleken:

- Bij biowassers met een pH van het waswater hoger dan 7,5 werd, zoals verwacht, een hogere emissie van ammoniak $\left(\mathrm{NH}_{3}\right)$ gevonden dan bij biowassers met een $\mathrm{pH}$ in de normale range van 6,5 tot 7,5 .

- Bij biowassers met een pH van het waswater lager dan 6,5 werd, zoals verwacht, een lagere emissie van ammoniak $\left(\mathrm{NH}_{3}\right)$ gevonden dan bij biowassers met een $\mathrm{pH}$ in de normale range van 6,5 tot 7,5. $\mathrm{Bij}$ de systemen met een lage $\mathrm{pH}$ werd een groot deel van de ammoniak-stikstof uit de stallucht uiteindelijk echter geëmitteerd als gasvormige stikstofoxiden ( $\mathrm{NO}_{\mathrm{y}}$ ). Een deel daarvan betrof de emissie van salpeterig zuur, $\mathrm{HNO}_{2}(\mathrm{~g})$, wat een vluchtig zuur is. Dit had tot gevolg dat de stikstofverwijdering van deze luchtwassers veel lager was dan op basis van de ammoniakverwijdering werd verondersteld (36\% i.p.v. 100\%). Aangenomen kan worden dat de emissie van stikstofoxiden (op molbasis $\mathrm{N}$ ) dezelfde stikstofdepositie tot gevolg heeft als de emissie van ammoniak; daarmee heeft het dezelfde eutrofiërende en verzurende werking als ammoniak.

Op basis van deze bevindingen volgt dat het zeer belangrijk is om de $\mathrm{pH}$ van een biowasser in de normale bedrijfsrange van 6,5 - 7,5 te houden. De $\mathrm{pH}$ waarde wordt reeds geregistreerd middels het elektronische monitoringssysteem, maar registratie alleen is niet voldoende. Het is van belang dat zowel de veehouder als de toezichthouder er op toezien dat de $\mathrm{pH}$ van het waswater zich in de praktijk daadwerkelijk in de juiste range bevindt en indien dit niet het geval is, de nodige actie onderneemt. Sinds enige tijd is het in Nederland toegestaan om een $\mathrm{pH}$ regeling toe te passen op luchtwassers om de $\mathrm{pH}$ binnen de gewenste range te houden door middel van zuur en loog. Overwogen zou kunnen worden om een dergelijke $\mathrm{pH}$-regeling te verplichten bij biowassers, zoals bijvoorbeeld ook in Duitsland het geval is.

Of de verschillende $\mathrm{pH}$ 's en het al dan niet toepassen van denitrificatie invloed hadden op de productie van lachgas $\left(\mathrm{N}_{2} \mathrm{O}\right)$, kon vanwege de beperkte steekproefomvang en hoge spreiding niet worden bepaald. Uit eerder onderzoek is bekend dat een denitrificatie-unit bij een luchtwasser tot hoge lachgasemissies kan leiden. 


\section{Bijlage 1 Metingen aan luchtwassers}

\begin{tabular}{|c|c|c|c|c|c|c|c|c|c|c|c|c|c|c|c|c|}
\hline \multirow[t]{4}{*}{ Categorie } & Datum & pH & Temp. & EC & NH3-in & NH3-uit & Verwijdering & N2O-in & N2O-uit & Deel van NH3-N & NOy-in & NOy-uit & Deel van NH3-N & Netto $\mathrm{N}$-tot & BWL number & Type \\
\hline & monstername & & & & & & & & & ingaand wat & & & ingaand wat & verwijdering & & \\
\hline & & & & & & & & & & als N2O emitteert & & & als NOy emitteert & & & \\
\hline & & $(-)$ & $\left({ }^{\circ} \mathrm{C}\right)$ & $(\mathrm{mS} / \mathrm{cm})$ & (ppm) & (ppm) & (\%) & (ppm) & (ppm) & (\%) & (ppm) & (ppm) & (\%) & (\%) & & \\
\hline \multirow[t]{9}{*}{ Lage pH: } & 12-Apr-2017 & 6.3 & n.b. & 13 & 27 & 0.0 & 100 & 0.47 & 1.38 & 6.7 & 0.09 & 9.46 & 34 & 61 & BWL 2007.02 & Bio-combi $85 \%$ NH3 \\
\hline & 13-Apr-2017 & 4.7 & n.b. & 7 & 16 & 0.0 & 100 & 0.56 & 0.83 & 3.4 & 0.07 & 13.11 & 82 & 16 & BWL 2009.12 & Bio-combi $85 \%$ NH3 \\
\hline & 18-Маy-2017 & 5.4 & 19 & 17 & 61 & 0.0 & 100 & 0.55 & 1.26 & 2.3 & 0.09 & 7.13 & 12 & 86 & BWL 2010.02 & Bio-combi $85 \%$ NH3 \\
\hline & 11-Oct-2017 & 2.8 & 19 & 15 & 28 & 0.0 & 100 & 0.46 & 1.24 & 5.6 & 0.03 & 17.15 & 61 & 35 & BWL 2010.02v2 & Bio-combi $85 \%$ NH3 \\
\hline & 18-Oct-2017 & 4.3 & 19 & 8 & 37 & 0.0 & 100 & 0.49 & 1.29 & 4.4 & 0.03 & 14.90 & 41 & 56 & BWL 2007.02.v1 & Bio-combi $85 \%$ NH3 \\
\hline & 23-Oct-2017 & 5.4 & 15 & 12 & 22 & 0.0 & 100 & 0.59 & 1.38 & 7.4 & 0.04 & 28.96 & 134 & -37 & BWL 2009.12v1 & Bio-combi $85 \%$ NH3 \\
\hline & Gemiddelde: & 4.8 & 18 & 12 & 32 & 0.0 & 100 & 0.52 & 1.23 & 4.5 & 0.06 & 15.12 & 61 & 36 & & \\
\hline & Stand.dev. & 1.2 & 2.0 & 4.0 & 15.9 & 0.0 & 0.0 & 0.05 & 0.20 & 1.9 & 0.03 & 7.69 & 43 & 43 & & \\
\hline & SEM: & 0.5 & 0.9 & 1.5 & 6.0 & 0.0 & 0.0 & 0.02 & 0.08 & 0.7 & 0.01 & 2.91 & 16 & 16 & & \\
\hline \multirow[t]{6}{*}{ Normale pH: } & 11-Apr-2017 & 6.8 & 16 & 16 & 14 & 6.4 & 55 & 1.13 & 1.11 & -0.3 & 0.07 & 0.10 & 0.2 & 51 & BWL 2007.02v1 & Bio-combi 85\% NH3 \\
\hline & 12-Apr-2017 & 7.4 & 16 & 11 & 23 & 7.8 & 67 & 0.50 & 0.69 & 1.6 & 0.11 & 0.15 & 0.2 & 64 & BWL 2008.04 / BB 96.10.042/046 & Biowasser 70\% NH3 \\
\hline & 11-May-2017 & 7.4 & 19 & 11 & 40 & 10.5 & 74 & 0.95 & 1.48 & 2.7 & 0.21 & 0.33 & 0.3 & 70 & BWL 2010.28 & Biowasser 70\% NH3 \\
\hline & Gemiddelde: & 7.2 & 17 & 13 & 26 & 8.2 & 65 & 0.86 & 1.09 & 1.8 & 0.13 & 0.19 & 0.2 & 62 & & \\
\hline & Stand.dev. & 0.3 & 1.7 & 2.5 & 13.0 & 2.1 & 9.3 & 0.32 & 0.40 & 1.5 & 0.07 & 0.12 & 0.1 & 9.7 & & \\
\hline & SEM: & 0.2 & 1.0 & 1.5 & 7.5 & 1.2 & 5.3 & 0.19 & 0.23 & 0.9 & 0.04 & 0.07 & 0.0 & 5.6 & & \\
\hline \multirow[t]{5}{*}{ Hoge pH: } & 16-May-2017 & 7.6 & 21 & 16 & 16 & 12.0 & 25 & 0.55 & 0.70 & 1.9 & 0.07 & 0.12 & 0.3 & 23 & BWL 2006.03v1 & Biowasser 70\% NH3 \\
\hline & 17-Мay-2017 & 7.7 & n.b. & 6 & 12 & 9.8 & 19 & 0.72 & 2.24 & 25.3 & 1.55 & 0.16 & -12 & 15 & BWL 2011.07 type B & Bio-combi $85 \%$ NH3 \\
\hline & Gemiddelde: & 7.6 & $n v t$ & 11 & 14 & 10.9 & 22 & 0.64 & 1.47 & 11.9 & 0.81 & 0.14 & -5.7 & 19 & & \\
\hline & Stand.dev. & 0.1 & $n v t$ & 7.5 & 2.8 & 1.6 & 4.4 & 0.12 & 1.09 & 16.6 & 1.05 & 0.03 & 8.5 & 5.6 & & \\
\hline & SEM: & 0.1 & $n v t$ & 5.3 & 2.0 & 1.1 & 3.1 & 0.08 & 0.77 & 11.7 & 0.74 & 0.02 & 6.0 & 4.0 & & \\
\hline \multirow[t]{7}{*}{ Denitrificatie: } & 2-May-2017 & 7.3 & 18 & 19 & 24 & 10.3 & 58 & 0.67 & 1.44 & 6.4 & 0.10 & 0.32 & 0.9 & 52 & BWL 2004.01 & Biowasser 70\% NH3 \\
\hline & 3-Мау-2017 & 7.7 & 15 & 11 & 20 & 9.0 & 54 & 0.96 & 1.01 & 0.5 & 0.10 & 0.11 & 0.0 & 51 & BWL 2007.02 & Bio-combi $85 \%$ NH3 \\
\hline & 15-May-2017 & 7.3 & 19 & 10 & 15 & 1.3 & 92 & 0.49 & 2.38 & 24.8 & 0.07 & 0.52 & 2.9 & 74 & BWL 2007.02 & Bio-combi 85\% NH3 \\
\hline & 24-May-2017 & 7.3 & 20 & 16 & 19 & 7.8 & 59 & 0.74 & 1.65 & 9.6 & 0.12 & 0.23 & 0.6 & 52 & BWL 2007.02.v1 & Bio-combi $85 \%$ NH3 \\
\hline & Gemiddelde: & 7.4 & 18 & 14 & 20 & 7.1 & 66 & 0.72 & 1.62 & 10.3 & 0.10 & 0.29 & 1.1 & 57 & & \\
\hline & Stand.dev. & 0.2 & 2.2 & 4.4 & 3.7 & 4.0 & 18 & 0.19 & 0.57 & 10.4 & 0.02 & 0.17 & 1.3 & 11 & & \\
\hline & SEM: & 0.1 & 1.1 & 2.2 & 1.8 & 2.0 & 8.8 & 0.10 & 0.29 & 5.2 & 0.01 & 0.09 & 0.6 & 5.6 & & \\
\hline
\end{tabular}




\section{Bijlage 2 Metingen aan luchtwassers (vervolg)}

\begin{tabular}{|c|c|c|c|c|c|c|c|c|}
\hline \multirow[t]{3}{*}{ Categorie } & Datum & $\mathrm{pH}$ & Temp. & EC & NH4-N & NO2-N & NO3-N & Berekende HNO2 (g) \\
\hline & monstername & & & & & & & evenwichtsconcentratie \\
\hline & & $(-)$ & $\left({ }^{\circ} \mathrm{C}\right)$ & $(\mathrm{mS} / \mathrm{cm})$ & $\mathrm{g} / \mathrm{l}$ & $\mathrm{g} / \mathrm{l}$ & $\mathrm{g} / \mathrm{l}$ & ppm \\
\hline \multirow[t]{9}{*}{ Lage pH: } & 12-Apr-2017 & 6.3 & n.b. & 13 & 2.09 & 3.83 & 0.15 & 4.72 \\
\hline & 13-Apr-2017 & 4.7 & n.b. & 7 & 0.69 & 0.67 & 0.70 & 37.61 \\
\hline & 18-May-2017 & 5.4 & 19 & 17 & 1.80 & 1.27 & 0.70 & 13.20 \\
\hline & 11-Oct-2017 & 2.8 & 19 & 15 & 1.02 & 0.00 & 1.41 & 1.72 \\
\hline & $18-O c t-2017$ & 4.3 & 19 & 8 & 0.76 & 0.10 & 0.74 & 13.04 \\
\hline & 23-Oct-2017 & 5.4 & 15 & 12 & 0.84 & 0.63 & 0.65 & 7.34 \\
\hline & Gemiddelde: & 4.8 & 18 & 12 & 1.20 & 1.08 & 0.72 & 12.94 \\
\hline & Stand.dev. & 1.2 & 2.0 & 4.0 & 0.59 & 1.42 & 0.40 & 12.91 \\
\hline & SEM: & 0.5 & 0.9 & 1.5 & 0.22 & 0.54 & 0.15 & 4.88 \\
\hline \multirow[t]{6}{*}{ Normale pH: } & 11-Apr-2017 & 6.8 & 16 & 16 & 2.88 & $<0.002$ & 2.16 & 0.00 \\
\hline & 12-Apr-2017 & 7.4 & 16 & 11 & 2.05 & 3.49 & 0.16 & 0.36 \\
\hline & 11-May-2017 & 7.4 & 19 & 11 & 1.94 & 3.71 & 0.02 & 0.42 \\
\hline & Gemiddelde: & 7.2 & 17 & 13 & 2.29 & $1.80-2.40$ & 0.78 & 0.26 \\
\hline & Stand.dev. & 0.3 & 1.7 & 2.5 & 0.51 & & 1.20 & 0.23 \\
\hline & SEM: & 0.2 & 1.0 & 1.5 & 0.30 & & 0.69 & 0.13 \\
\hline \multirow[t]{5}{*}{ Hoge pH: } & 16-May-2017 & 7.6 & 21 & 16 & 2.05 & 0.02 & $<0.010$ & 0.00 \\
\hline & 17-May-2017 & 7.7 & n.b. & 6 & 0.57 & 0.59 & 0.02 & 0.03 \\
\hline & Gemiddelde: & 7.6 & & 11 & 1.31 & 0.31 & 0.01 & 0.02 \\
\hline & Stand.dev. & 0.1 & & 7.5 & 1.04 & 0.40 & & 0.02 \\
\hline & SEM: & 0.1 & & 5.3 & 0.74 & 0.28 & & 0.02 \\
\hline \multirow[t]{7}{*}{ Denitrificatie: } & 2-May-2017 & 7.3 & 18 & 19 & 3.35 & 5.71 & 0.21 & 0.74 \\
\hline & 3-May-2017 & 7.7 & 15 & 11 & 1.92 & 1.77 & 0.87 & 0.09 \\
\hline & 15-May-2017 & 7.3 & 19 & 10 & 0.30 & 0.36 & $<0.002$ & 0.05 \\
\hline & 24-May-2017 & 7.3 & 20 & 16 & 1.41 & 0.23 & 1.38 & 0.03 \\
\hline & Gemiddelde: & 7.4 & 18 & 14 & 1.74 & 2.02 & $0.61-0.82$ & 0.23 \\
\hline & Stand.dev. & 0.2 & 2.2 & 4.4 & 1.26 & 2.56 & & 0.34 \\
\hline & SEM: & 0.1 & 1.1 & 2.2 & 0.63 & 1.28 & & 0.17 \\
\hline
\end{tabular}




\section{Literatuur}

Burton, S. A. Q.; I. Prosser (2001). Autotrophic ammonia oxidation at low pH through urea hydrolysis. Appl. Environ. Microbiol. 67:2952-2957.

De Boer, W.; P.J.A. Klein Gunnewiek; M. Veenhuis; E. Bock; H.J. Laanbroek (1991). Nitrification at Low pH by Aggregated Chemolithotrophic Bacteria. Appl Environ Microbiol. 57(12): 3600-3604.

Groeneweg, J.; I. Leuther; T. Muckenheim (1996). Nitric Oxide (NO) release in activated sludge plants with nitrification and denitrification. In: Progress in Nitrogen Cycling Studies. Developments in Plant and Soil Sciences. Eds: O. van Cleemput, G. Hofman, A. Vermoesen. Volume 68, 1996, $553-$ 557.

Harrison R.M. (1986) Secondary pollutants. In: Harrison R.M., Perry R. (eds) Handbook of Air Pollution Analysis. Springer, Dordrecht

Melse, R.W.; Mosquera, J. (2014). Nitrous oxide (N2O) emissions from biotrickling filters used for ammonia removal at livestock facilities. Water Science \& Technology 69(5), 994-1003.

Melse, R.W.; Ogink, N.W.M. (2005). Air scrubbing techniques for ammonia and odor reduction at livestock operations : review of on-farm research in the Netherlands. Transactions of the ASAE 48(6), 2303-2313.

Melse, R.W.; Schalk, J.A.C. , Bartels, A.A. (2015). Onderzoek naar aanwezigheid van legionella in biologische luchtwassers bij stallen. Wageningen UR Livestock Research, rapport 891.

Melse, R.W., Ellen, H., Nijeboer, G.M., Ploegaert, J.P.M. (2012a). Vergelijking rendementsmetingen bij luchtwassers - Natchemisch versus gasdetectiebuisjes. Livestock Research, Wageningen. Gepubliceerd als bijlage van rapport "Innovatieproject Doelmatig gebruik luchtwassers Eindverslag. DLV Intensief Advies BV/DLV Rundvee Advies BV, 13 maart 2012".

Melse, R. W.; Van Hattum, T. G.; Huis in 't Veld, J. W. H.; Gerrits, F. A. (2012b). Metingen aan twee luchtwassystemen in een vleeskuikenstal met conditionering van ingaande ventilatielucht. Rapport 503. Wageningen UR Livestock Research, Lelystad.

Melse, R.W.; J.M.G. Hol, G.M. Nijeboer (2012c). Metingen aan een experimentele biologische luchtwasser met denitrificatie bij een vleesvarkensstal. Rapport 554. Wageningen UR Livestock Research, Lelystad.

Mosquera, J.; J.M.G. Hol; J.P.M. Ploegaert; T. van Hattum; E. Lovink; N.W.M. Ogink (2012). Emissies uit een vleeskuikenstal met geconditioneerd luchtinlaat, biologische wasser en denitrificatie-unit. Meetprogramma Integraal Duurzame Stallen. Rapport 611. Wageningen UR Livestock Research, Lelystad.

Mørkved, P.T.; P. Dörsch; L.R. Bakken (2007). The N2O product ratio of nitrification and its dependence on long-term changes in soil pH. Soil Biology and Biochemistry 39(8): 2048-2057.

Mol, G.; Ogink, N.W.M. (2002). Geuremissies uit de veehouderij II : overzichtsrapportage 2000-2002. IMAG rapport 2002-09, Wageningen.

Painter, H. A (1986). Nitrification in the treatment of sewage and wastewaters, pp 185-211. In :J. I. Prosser (ed.), Nitrification. IRL Press, Oxford, United Kingdom.

Shammas, N.K. (1986). Interactions of Temperature, $\mathrm{pH}$, and Biomass on the Nitrification Process. Journal (Water Pollution Control Federation) 58(1): 52-55.

Tarre, S.; M. Green (2004). High-Rate Nitrification at Low pH in Suspended- and Attached-Biomass Reactors. Appl Environ Microbiol. 70(11): 6481-6487.

Tarre, S.; M. Beliavski; N. Denekamp; A. Gieseke; D. de Beer; M. Green (2004). High nitrification rate at low $\mathrm{pH}$ in a fluidized bed reactor with chalk as the biofilm carrier. Water Sci Technol. 49(1112): $99-105$

Van der Heyden, C. (2017). Operation and characterization of air scrubbers for the emission reduction of ammonia, hydrogen sulphide and greenhouse gases from animal housing systems. PhD thesis. Ghent University, België. 


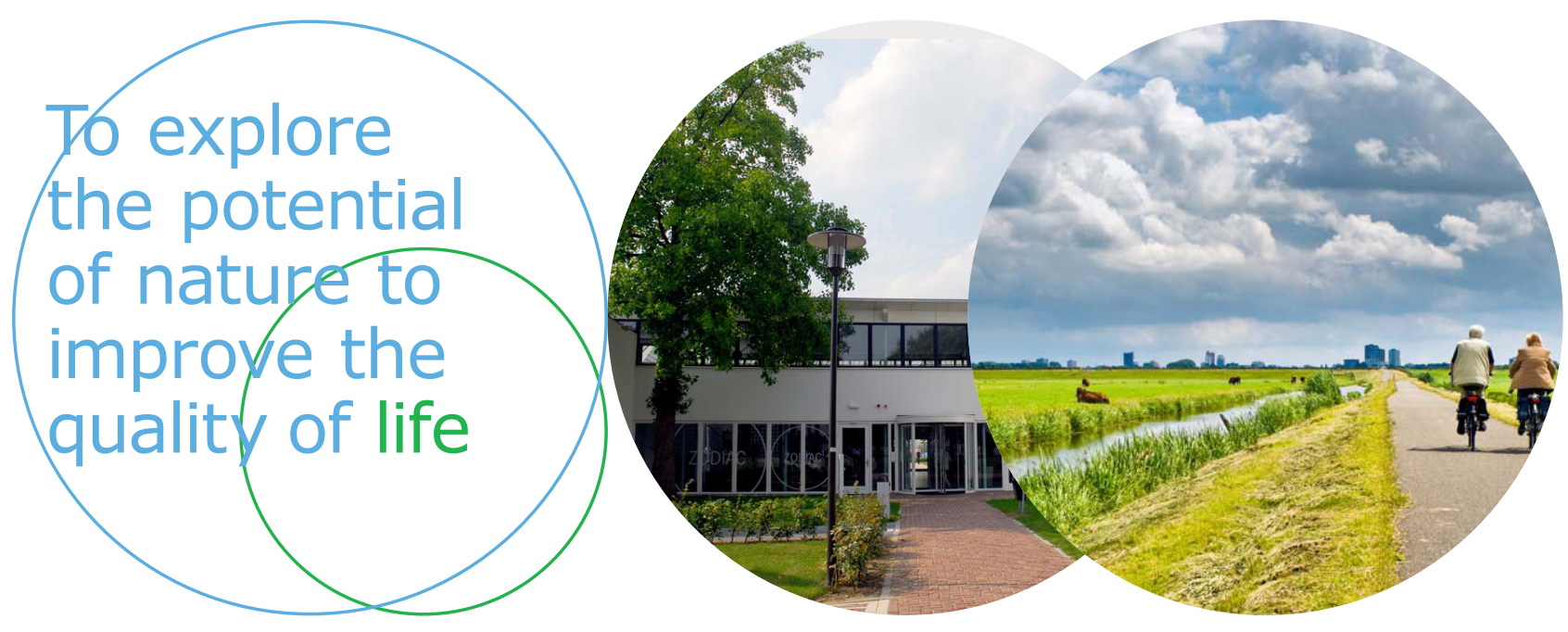

Wageningen Livestock Research Postbus 338

Wageningen Livestock Research ontwikkelt kennis voor een zorgvuldige en 6700 AH Wageningen

T 0317483953

E info.livestockresearch@wur.nl www.wur.nl/ livestock-research renderende veehouderij, vertaalt deze naar praktijkgerichte oplossingen en innovaties, en zorgt voor doorstroming van deze kennis. Onze wetenschappelijke kennis op het gebied van veehouderijsystemen en van voeding, genetica, welzijn en milieu-impact van landbouwhuisdieren integreren we, samen met onze klanten, tot veehouderijconcepten voor de $21 \mathrm{e}$ eeuw.

De missie van Wageningen University \& Research is 'To explore the potential of nature to improve the quality of life'. Binnen Wageningen University \& Research bundelen 9 gespecialiseerde onderzoeksinstituten van Stichting Wageningen Research en Wageningen University hun krachten om bij te dragen aan de oplossing van belangrijke vragen in het domein van gezonde voeding en leefomgeving. Met ongeveer 30 vestigingen, 6.500 medewerkers en 10.000 studenten behoort Wageningen University \& Research wereldwijd tot de aansprekende kennisinstellingen binnen haar domein. De integrale benadering van de vraagstukken en de samenwerking tussen verschillende disciplines vormen het hart van de unieke Wageningen aanpak. 